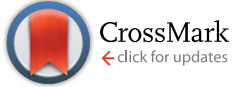

Cite this: RSC Adv., 2017, 7, 14761
Received 19th February 2017 Accepted 1st March 2017

DOI: 10.1039/c7ra02061a

rsc.li/rsc-advances

\section{Improved electrical conductivity of PDMS/SCF composite sheets with bolting cloth prepared by a spatial confining forced network assembly method}

\author{
Xiaolong Gao, ${ }^{a}$ Yao Huang, ${ }^{\text {*a }}$ Ying Liu, ${ }^{\text {ab }}$ Semen Kormakov, ${ }^{a}$ Xiuting Zheng, ${ }^{\text {ac }}$ Dan $\mathrm{Wu}^{\mathrm{a}}$ \\ and Daming $\mathrm{Wu}^{\star \mathrm{ab}}$
}

A novel method of Spatial Confining Forced Network Assembly (SCFNA) for preparation of high-performance electrically conductive polymeric composites was proposed in this paper. Differing from the self-assembly mechanism, as in traditional compounding processes, the SCFNA process could provide conductive fillers with an effective forced networking assembly action to get a more compacted network. High electroconductive polydimethylsiloxane (PDMS)/short carbon fiber (SCF) binary composites with a low percolation threshold of $0.15 \mathrm{wt} \%$ were prepared by the SCFNA method. A rapid increase in electrical conductivity from $1.71 \times 10^{-12} \mathrm{~S} \mathrm{~m}^{-1}$ of PDMS to $1.67 \times 10^{2} \mathrm{~S} \mathrm{~m}^{-1}$ was achieved with $4 \mathrm{wt} \%$ short carbon fibers. It was shown that a continuous and compact SCF network was built in a PDMS matrix. Furthermore, when the bolting cloth as a sarking was co-compressed with the mixture, a much lower percolation threshold of $0.06 \mathrm{wt} \%$ and a higher electrical conductivity of $3.22 \times 10^{2} \mathrm{~S} \mathrm{~m}^{-1}$ with $4 \mathrm{wt} \%$ of SCF were obtained due to volume exclusion. Compared with the conventional compounding method, the electro-conductive properties of the composites prepared by the above mentioned method can be enhanced up to several times, or even by orders of magnitudes. Moreover, if the mesh number of the bolting cloth is large enough, the carbon fibers will be impeded from penetrating the bolting cloth together with the polymer when they are co-compressed, thus an electrically conductive film with single or double insulating face could be prepared through this method.

\section{Introduction}

Electrically conductive polymeric composites (CPCs) have attracted great interest in many applications such as energy storage, batteries, three-dimensional printing materials, electromagnetic shielding, flexible displays and smart sensors. ${ }^{1-13}$ The theory and practice have shown that constructing a continuous and compact network of conductive fillers in a polymeric matrix is essential to prepare composites with high conductivity. ${ }^{14-20}$ It is a conventional method to construct such a network mainly by increasing the amount of conductive fillers until percolation appears. ${ }^{14-16,21-24}$ As most polymers have very low electrical conductivity, the electrically conductive fillers are incorporated into polymers to fabricate CPCs. Many efforts have been focused on how to build conductive networks in polymer matrixes using electrically conductive fillers with high aspect ratio, including

${ }^{a}$ College of Mechanical and Electrical Engineering, Beijing University of Chemical Technology, Beijing 100029, China. E-mail: wudaming@vip.163.com; hy06@163. com; Fax: +86-10-64435015; Tel: +86-10-64435231

${ }^{b}$ State Key Laboratory of Organic-Inorganic Composites, Beijing University of Chemical Technology, Beijing 100029, China

'Polymer Material Processing Equipment Engineering Research Center of the Ministry of Education, Beijing 100029, China carbon black particles, carbon fiber, graphite flake, carbon nanotubes (CNTs) and graphene. ${ }^{14,15,17,25-33}$

Generally, there are mainly three approaches to obtain a continual conductive network. A widely adopted processing technology is to increase the fraction of the conductive fillers to a certain value until the percolation threshold appears. ${ }^{13-16}$ Another method is to adopt a system of two immiscible polymers and conductive fillers. ${ }^{34,35}$ With suitable fraction ratio of the two polymers and thermodynamic conditions, a co-continuous two-phase structure with selected location of the fillers in one polymer could be obtained, which serves as continuous conductive network. Recently, Yan et al. ${ }^{35}$ reported improved electrical conductivity of polyamide 12/ graphene nanocomposites with maleated polyethyleneoctene rubber prepared by melt compounding, both higher electrical conductivity and storage modulus were obtained when most graphene sheets were located in PA12 matrix rather than that in POE- $g$-MA phase. The third method is to form a segregated structure in the composites by compressing a mixture of polymer granules decorated with conductive fillers via dry or solution mixing to construct the segregated conductive networks. ${ }^{16,36,37}$ In spite of a notable increase in electrical conductivity at percolation loading, the composites 
still demonstrate much lower electrical conductivity than theoretically predicted. ${ }^{20,38-40}$

PDMS has been widely used as the elastomeric substrate for stretchable electronics. Recently, many researchers use PDMS or other Si-elastomers as the matrix of high performance conductive stretchable composites. Kato et al. ${ }^{41}$ prepared a highly conductive elastomer by loading a low content ( $1 \mathrm{wt} \%)$ of a long singlewalled carbon-nanotube into conductive silicone rubber, and this material has a higher mechanical strength than commercialized generic stocking. It indicated that the rubbers would become brittle to lose its mechanical properties when incorporating the conductive fillers at high loading levels, therefore a high conductive network with a low content of fillers is necessary for a highly conductive elastomer. Han et al. ${ }^{42}$ reported an efficient and simple method to fabricate lightweight and flexible composites composed of a reduced graphene oxide aerogel film (rGO-AF) and PDMS. Single and multilayer rGO-AF/ PDMS composites were fabricated by liquid PDMS infiltrating and curing. Zhu et al.$^{43}$ reported a simple route for preparation of cotton-AgNWs-PDMS stretchable conductor was explored through the dip-coating method. Both excellent electrical and mechanical properties were obtained as the combination of an interconnected porous structure of cotton as skeleton with supported 2D AgNWs networks. But conductivity of this material seems to be difficult to control and the filler of AgNWs is too expensive despite its high conductivity.

In this paper, a novel method of Spatial Confining Forced Network Assembly (SCFNA) was used to prepare PDMS/SCF CPCs, which was focused on constructing a more compacted electrically conductive network to enhance the electrical conductivity of polymer composites significantly. The main idea of SCFNA was introducing a mechanical delivered additional interaction to carry out a forced assembly of conductive network. Furthermore, the addition of high-strength bolting cloth and carbon fibers leads composites to excellent mechanical properties. As PDMS could penetrate through the bolting cloth and carbon fibers could not when they are co-compressed, the volume exclusion effect was achieved. Thus a higher electrically conductive film with single or double insulating face can be prepared in this way. This method is not only suitable for the preparation of thermosetting resin conductive composite sheets, but also effective on the preparation of other polymer-based conductive composite sheets, such as thermoplastic polypropylene, nylon, etc. As to thermal conductive composites, reinforcing and toughening composites, it may provide some valuable reference. However, it must be pointed out that just sheet samples were obtained from early experiments. Although we have try many times to prepare highly electrical conductive composites with a certain thickness by laminating and it achieved good results, but if you want to use this method to prepare different shapes and dimension products, it need further research.

\section{Experimental}

\section{Materials used}

PDMS with a trade name of SYLGARD 184 SILICONE ELASTOMER was obtained from DOW CORNING, USA. Its density and curing temperature are $1.03 \mathrm{~g} \mathrm{~cm}^{-3}$ at $25^{\circ} \mathrm{C}$ and on range of $25-150{ }^{\circ} \mathrm{C}$. Short carbon fibers with $7 \mu \mathrm{m}$ diameter and $4 \mathrm{~mm}$ length were provided by Toray, Japan. Its electrical conductivity is $2.6 \times 10^{4} \mathrm{~S} \mathrm{~m}^{-1}$. Bolting cloth with different meshes was bought from Shanghai Xinhua Filter Development Trade Co., Ltd (China).

\section{Composite preparation}

The experimental hot embossing device was designed, which could provide a pressing force up to $50 \mathrm{kN}$ with a pressing speed of $0.005 \mathrm{~mm} \mathrm{~s}^{-1}$ to $0.5 \mathrm{~mm} \mathrm{~s}^{-1}$. The servo motor of this embossing device was accurately controlled by a PLC system and the position accuracy of $\pm 3 \mu \mathrm{m}$ for the up platen was guaranteed. The compressing mold was made of two flat plates with electrical heaters and the surface of the plates can be smooth or micro/nano structured on both or one of their surfaces. The temperature of the molds can be controlled from ambient temperature to $220^{\circ} \mathrm{C}$ with a control accuracy of $\pm 1^{\circ} \mathrm{C}$. The effective working area was $160 \times 80 \mathrm{~mm}$.

Prior to internal mixing, SCF was dried at $100{ }^{\circ} \mathrm{C}$ under vacuum for $1 \mathrm{~h}$. PDMS and SCF were mixed to get a homogeneously dispersed mixture in a HAAKE MiniLab conical twin-screw mixer at $25{ }^{\circ} \mathrm{C}$ with a rotational speed of $50 \mathrm{rpm}$ for $15 \mathrm{~min}$. Then the vacuum pump was used to remove the air bubbles from the homogeneously dispersed mixture. In order to investigate the SCF location and dispersion in PDMS matrix and its effect on electrical and mechanical properties, the CPCs prepared by compounding process, SCFNA process and SCFNA with bolting cloth process were designated as P1, P2 and P3, respectively.

Compounding process (P1). The homogeneously dispersed mixture was heat curing molded at $120^{\circ} \mathrm{C}$ for 15 min to prepare specimens for testing.

SCFNA process (P2). The homogeneously dispersed mixture was placed in a confining space of a compression mold with micro-nano structured array to carry out two-stage compressing. In first stage, it was compression-molded to a thickness of 1 $\mathrm{mm}$ with a proper speed within 60 seconds and staying for 3 to $5 \mathrm{~min}$. At the second stage, the composite was further compression-molded to a thickness of $100 \mu \mathrm{m}$ within 60 seconds. It's important to note that the compound of polymer and fillers needs to be kept as flow state in the whole process of compression. Finally, it was heat curing molded at $120{ }^{\circ} \mathrm{C}$ for 10 min to obtain specimens for testing.

SCFNA with bolting cloth process (P3). Based on the above two-stage compressing steps, the homogeneous dispersed compound and bolting cloth as a sarking was co-compressionmolded to a calculated thickness range from $150 \mu \mathrm{m}$ to $450 \mu \mathrm{m}$. The difference is that compression mold surface is smooth, then it was heat curing molded at $120{ }^{\circ} \mathrm{C}$ for 10 min to obtain specimens for testing. The prepared PDMS/SCF binary composite sheets with the thickness of $150 \mu \mathrm{m}, 250 \mu \mathrm{m}, 350$ $\mu \mathrm{m}, 450 \mu \mathrm{m}$ were designated as $\mathrm{T} 1, \mathrm{~T} 2, \mathrm{~T} 3$ and $\mathrm{T} 4$, respectively.

\section{Characterizations}

Morphology. A Video Measuring System JTVMS-1510T made by Dongguan JATEN Precision Instrument Co., Ltd (China) was 
used to investigate the formation situation of carbon fibers conductive network in PDMS matrix and measure the thread diameter of the network. A Hitachi S4700 scanning electron microscopy (SEM) at an accelerating voltage of $30 \mathrm{kV}$ was used to study the dispersion and location of the carbon fibers in composite sheets section.

Electrical conductivity. Direct current (DC) electrical conductivities of the PDMS/SCF composites with higher conductivities than $10^{-6} \mathrm{~S} \mathrm{~m}^{-1}$ were measured by Keithley 4200 SCS (America) with a standard four probe method, while electrical conductivities of the PDMS/SCF composites with lower conductivities than $10^{-6} \mathrm{~S} \mathrm{~m}^{-1}$ were measured by a ZC-90D resistivity meter from Shanghai Taiou Electronics (China). Surface resistivity of the PDMS/SCF composites with higher resistivity than $10^{4} \Omega$ were also measured by above ZC-90D resistivity meter, while surface resistivity of the PDMS/SCF composites with lower resistivity than $10^{4} \Omega$ were measured by a M8812 Maynuo DC Source Meter from Nanjing Maynuo company (China) with a standard electrode.

Mechanical properties. The mechanical properties of the PDMS/SCF composites were tested with an electrical universal material testing machine UTM-1422, Chengde Jinjian Testing Instrument Co., Ltd.

\section{Results and discussion}

For convenience, we defined the thickness of average diameter of the network threads as a characteristic diameter $(\mathrm{dm})$. The procedure of SCFNA involves three steps, as shown in Fig. 1. Firstly, the polymer and conductive fillers were mixed by melt compounding or solution mixing to get a homogeneously dispersed mixture. Secondly, the homogeneously dispersed mixture was compressed by a pressing mold to initiate and finish the networking of the conductive filler by normal selfassembly mechanism. Thirdly, the sample was further compressed after forming a self-assembled network until to the thickness less than characteristic diameter. When the thickness of samples is much large than characteristic diameter $(h>\mathrm{dm})$, it is called free compression which could only cause the selfassembly network wiggling in polymer matrix without estimable densification of the network threads. When the sample was compressed to a thickness less than characteristic diameter $(h<\mathrm{dm})$, a noteworthy densification of the network threads could be come into being by spatial confining compression, as shown in Fig. 2. Simultaneously an array anchoring action is applied to the conductive network with the help of micro-nano structured array on the surface of pressing mold, which provides additional enhancement in compactness of the network at anchoring locations. It's important to note that the mixture of polymer and fillers needs to be kept as flow state in the whole process of compression.

Fig. 3 shows the relationships between direct current (DC) electrical conductivity and filler content of PDMS/SCF composite sheets by different processes of P1, P2 and P3, which follows the conductive percolation theory. ${ }^{21-24}$ When the filler content is low, the change of the composites conductivity is not obvious. With the filler content increasing to a certain degree, a dramatic improvement of magnitude in the conductivity of composites happens, which changes the polymer from insulator to conductor. Then a small change of the filler content will cause a large fluctuation in the conductivity of the composites. Above the percolation area, conductivity of the composites changes little again with increase of filler content. An integrated conductive network is built in polymer matrix, which brings high conductivity. The percolation threshold values of the composites prepared by different processes of P1,

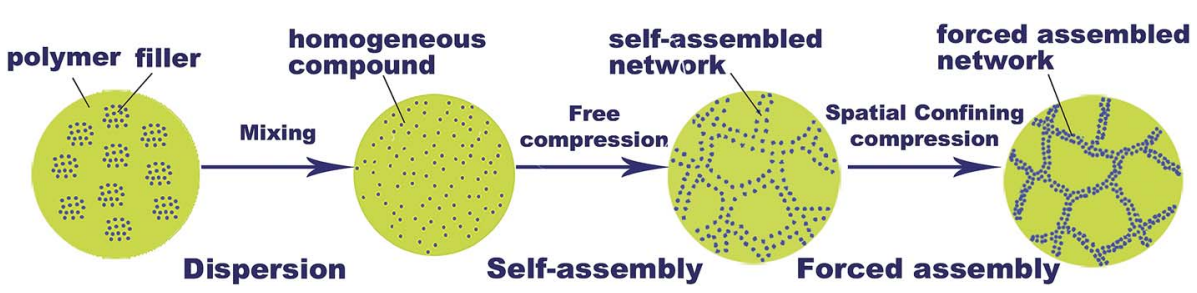

Fig. 1 The process of the SCFNA method.

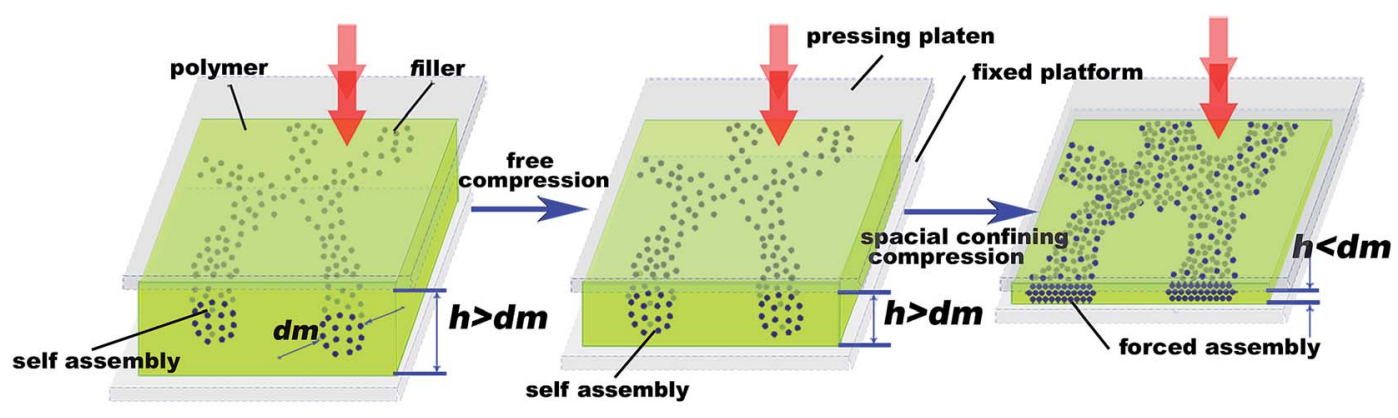

Fig. 2 Free compression and spatial confining compression of self-assembled network. 


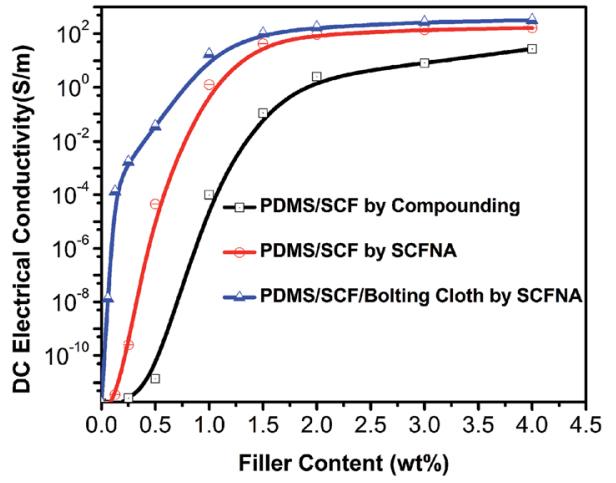

Fig. 3 Direct current (DC) electrical conductivity versus SCF content for PDMS/SCF composites by different processes including compounding process, SCFNA process, SCFNA with bolting cloth process. The $y$ coordinate of direct current (DC) electrical conductivity is a logarithmic coordinate.

P2 and P3 are $0.45 w t \%, 0.15 w t \%, 0.06 w t \%$, respectively. As shown in the curve, the PDMS/SCF composite sheets prepared by the SCFNA process (P2) exhibit a rapid transition from electrically insulating to conducting with a low percolation threshold of $0.15 \mathrm{wt} \%$, implying the formation of a continuous and compact SCF network for electrons transport in the matrix. The addition of bolting cloth further improved the electrical conductivity of the PDMS/SCF composite sheets with a lower percolation threshold of $0.06 \mathrm{wt} \%$, which is much lower than PA12/MWNT nanocomposites prepared by melt compounding (0.9 wt\%) reported by Socher et al., ${ }^{\mathbf{4 4}}$ and polyamide $12 /$ graphene nanocomposites with maleated polyethylene-octene rubber $(0.65 \mathrm{wt} \%)$ reported by Yan et al. ${ }^{35}$ The electrical conductivity $(\sigma)$ follows the power law at loadings near the percolation threshold $\left(\varphi_{\mathrm{c}}\right){ }^{45}$

$$
\sigma \propto \sigma_{0}\left(\varphi-\varphi_{\mathrm{c}}\right)^{n}
$$

where $\sigma_{0}$ is the electrical conductivity of conductive fillers, $\varphi$ is the weight fraction of fillers above $\varphi_{\mathrm{c}}$ and $n$ is the critical exponent describing the rapid variation of $\sigma$ near percolation threshold. The conductivities of PDMS/SCF composite sheets agree with the percolation behavior predicted by eqn (1). When $\varphi_{\mathrm{c}}=0.45 \mathrm{wt} \%$ and $n=2.5(\mathrm{P} 1), \varphi_{\mathrm{c}}=0.15 \mathrm{wt} \%$ and $n=3.13(\mathrm{P} 2)$, $\varphi_{\mathrm{c}}=0.06 \mathrm{wt} \%$ and $n=12.14(\mathrm{P} 3)$, the straight line fits well with the experimental data. The composite sheets prepared by P2 and $\mathrm{P} 3$ process with only $0.5 \mathrm{wt} \%$ SCF exhibits a high conductivity of $4.5 \times 10^{-5} \mathrm{~S} \mathrm{~m}^{-1}$ and $3.55 \times 10^{-2} \mathrm{~S} \mathrm{~m}^{-1}, 6$ to 9 orders of magnitude higher than that of $1.40 \times 10^{-11} \mathrm{~S} \mathrm{~m}^{-1}$ of the composites by P1 process with the same weight fraction of fillers. When the loading of SCF is $1.5 \mathrm{wt} \%$, the conductivity approaches to $4.32 \times 10^{1} \mathrm{~S} \mathrm{~m}^{-1}$ and $1.03 \times 10^{2} \mathrm{~S} \mathrm{~m}^{-1}$ which are even higher than that of the PDMS/4 wt\% SCF composites by P1 process, respectively. That is to say, high-performance electroconductive polymeric composite sheets were prepared by $\mathrm{P} 2$ and $\mathrm{P} 3$ process with a low weight fraction of fillers from $0.5 \mathrm{wt} \%$ to $1.5 \mathrm{wt} \%$ compared with $\mathrm{P} 1$ process. The efficiency of the SCFNA method (P2) in improving conductivity of PDMS/SCF composites is much more than the compounding method (P1). Especially the addition of bolting cloth (P3) further improved the electrical conductivity.

The average gap of the conducting fillers in the network plays a crucial role in all of parameters and conditions affecting the level of conductivity of the composites. The transmission mechanism of electrons between adjacent particles of conductive fillers in polymeric matrix is explained as an ohmic conduction with an average gap between adjacent particles less than or equal to $10 \AA$ on the basis of Franckel's theory, and nonohmic transmission of tunneling effect or electron emission from one particle to the next with an average gap beyond 10 A. ${ }^{31,38}$ Up to now rare morphology of conductive network of either microscale fillers or nanoscale fillers with average gap of less than or equal to $10 \AA$ between adjacent particles prepared by existing compounding methods was reported. Adequate theoretical and experiment investigations had quantitatively proven the conclusive effect of the gap between adjacent particles on the conductivity of the composites. ${ }^{15-18,38-40,44,46}$ Nevertheless, it is so disappointed that the existing prediction models avoided the most important parameter of average gap between conducting fillers. However, in this paper, many efforts have been focused on how to decrease the average gap of the conducting fillers to build a continuous and compact network in a polymer matrix. According to the SEM micrographs of PDMS/4 wt\% SCF composites section by P1, P2, P3, respectively (Fig. 4ac), the distribution states of carbon fibers in PDMS matrix and the average gap of adjacent fibers are different in the composites. Fig. 4a reveals that carbon fibers are homogeneously dispersed in PDMS. The average gap of adjacent carbon fibers in the network is greater than $20 \mu \mathrm{m}$, implying the SCF conductive network in the PDMS matrix by P1 process is not compact enough. Because the possible aggregation force of the filler, including van der Waals force, liquid bridge, electrostatic force, hydrogen bond, is not large enough to repel all polymer away in between. The network by such a self-assembly mechanism could not be very compacted, which is the main reason of limited conductivity of the polymeric composites by present compounding technology. While for P2, differing from selfassembly mechanism, as in traditional compounding process (P1), Fig. 4b reveals that carbon fibers are dispersed regularly in PDMS with obvious reunion phenomenon in certain spacing and carbon fibers agglomerate into a circle like the section of network cable as shown in the inset of three circles on Fig. 4b. The average gap of adjacent carbon fibers in the network is less than $5 \mu \mathrm{m}$ by statistical calculation of fibers in the circles. Moreover, it provided an additional enhancement in compactness of the network at anchoring locations with the help of micro-nano structured array on the surface of compressing mold, which left grooves on the surface of materials. In this way the self-assembly network is assembled more tightly to form a forced-assembly network with enhanced electric conductivity. Furthermore, an insulating surface layer composed of bolting cloth was co-compressed with the composite (P3). The adjacent fillers at the network were forced to be more closely at the salient points of the bolting cloth to provide additional anchoring act with the help of the bolting cloth under the plate. 


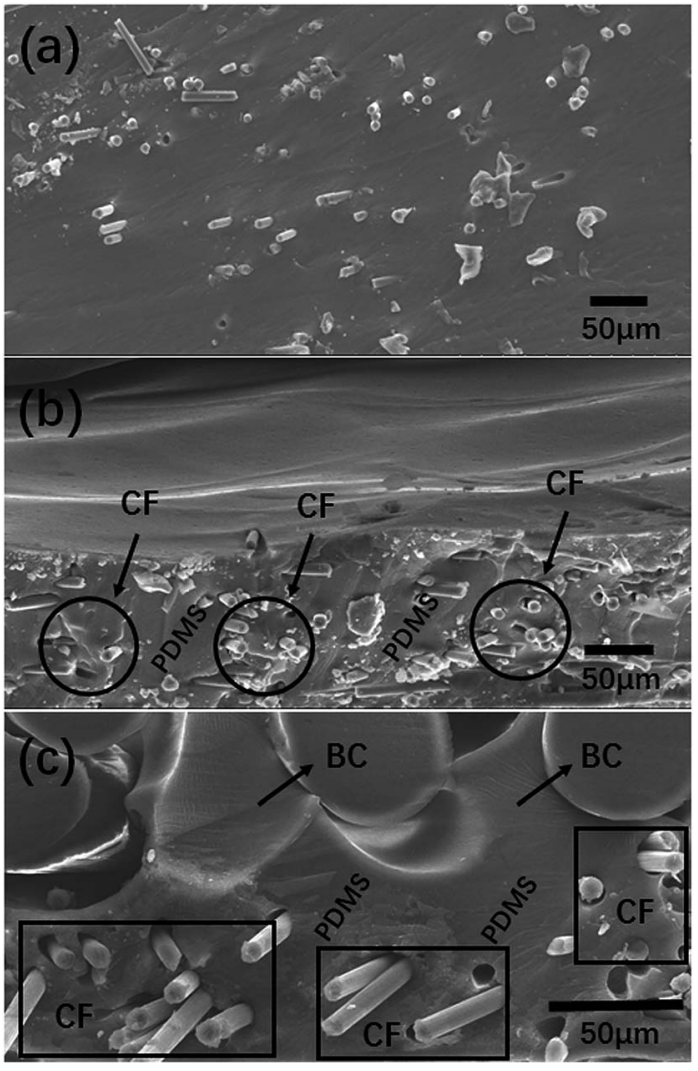

Fig. 4 (a-c) SEM micrographs of PDMS/4 wt\% SCF composites section by $\mathrm{P} 1, \mathrm{P} 2, \mathrm{P} 3$, respectively. $\mathrm{BC}$ is bolting cloth.

The average gap of adjacent carbon fibers in the network is less than $1 \mu \mathrm{m}$, implying a more compact SCF conductive network was built in PDMS matrix compared with the composites by P2 without bolting cloth. As PDMS could penetrate through the bolting cloth and carbon fibers could not (Fig. 4c). The PDMS/ SCF composite sheets with a higher electrical conductivity were prepared due to volume exclusion.

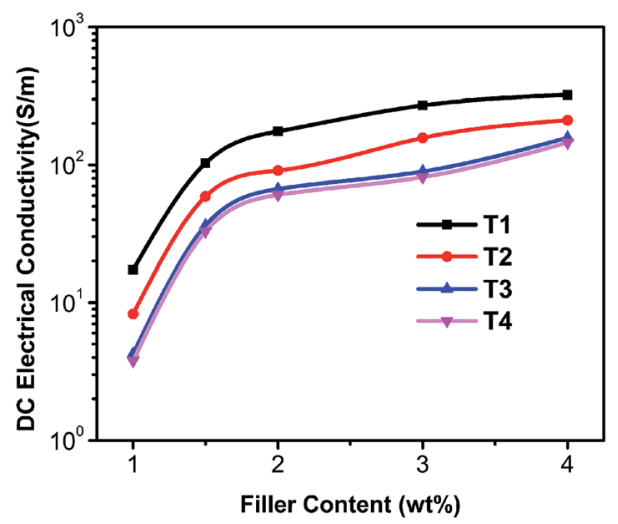

Fig. 5 Direct current (DC) electrical conductivity versus SCF content for PDMS/SCF composites of T1, T2, T3 and T4 by the SCFNA with bolting cloth process (P3), the $y$ coordinate of direct current (DC) electrical conductivity is a logarithmic coordinate. (T1) PDMS/SCF with thickness of $150 \mu \mathrm{m}$. (T2) PDMS/SCF with thickness of $250 \mu \mathrm{m}$. (T3) PDMS/SCF with thickness of $350 \mu \mathrm{m}$. (T4) PDMS/SCF with thickness of $450 \mu \mathrm{m}$.
Table 1 The conductivity values for PDMS/SCF composite sheets of $\mathrm{T} 1, \mathrm{~T} 2, \mathrm{~T} 3$ and T4 by the SCFNA with bolting cloth process compared with the compounding process (P1)

\begin{tabular}{lllrlll}
\hline \multirow{2}{*}{$\begin{array}{l}\text { Filler content } \\
\text { (wt\%) }\end{array}$} & \multicolumn{6}{l}{ DC electrical conductivity $\left(\mathrm{S} \mathrm{m}^{-1}\right)$} \\
\cline { 2 - 7 } & $\mathrm{T} 1$ & $\mathrm{~T} 2$ & $\mathrm{~T} 3$ & $\mathrm{~T} 4$ & $\mathrm{P} 1$ & Increase \\
\hline 1 & 17.28 & 8.28 & 4.24 & 3.78 & 0.0001 & 173000 \\
1.5 & 103.2 & 59 & 36.2 & 32.8 & 0.11 & 938.2 \\
2 & 175.2 & 91 & 66.8 & 60.6 & 2.5 & 70.1 \\
3 & 271 & 157.4 & 89.8 & 81.6 & 8.1 & 33.5 \\
4 & 322 & 211 & 157.6 & 145.4 & 2.7 & 11.6
\end{tabular}
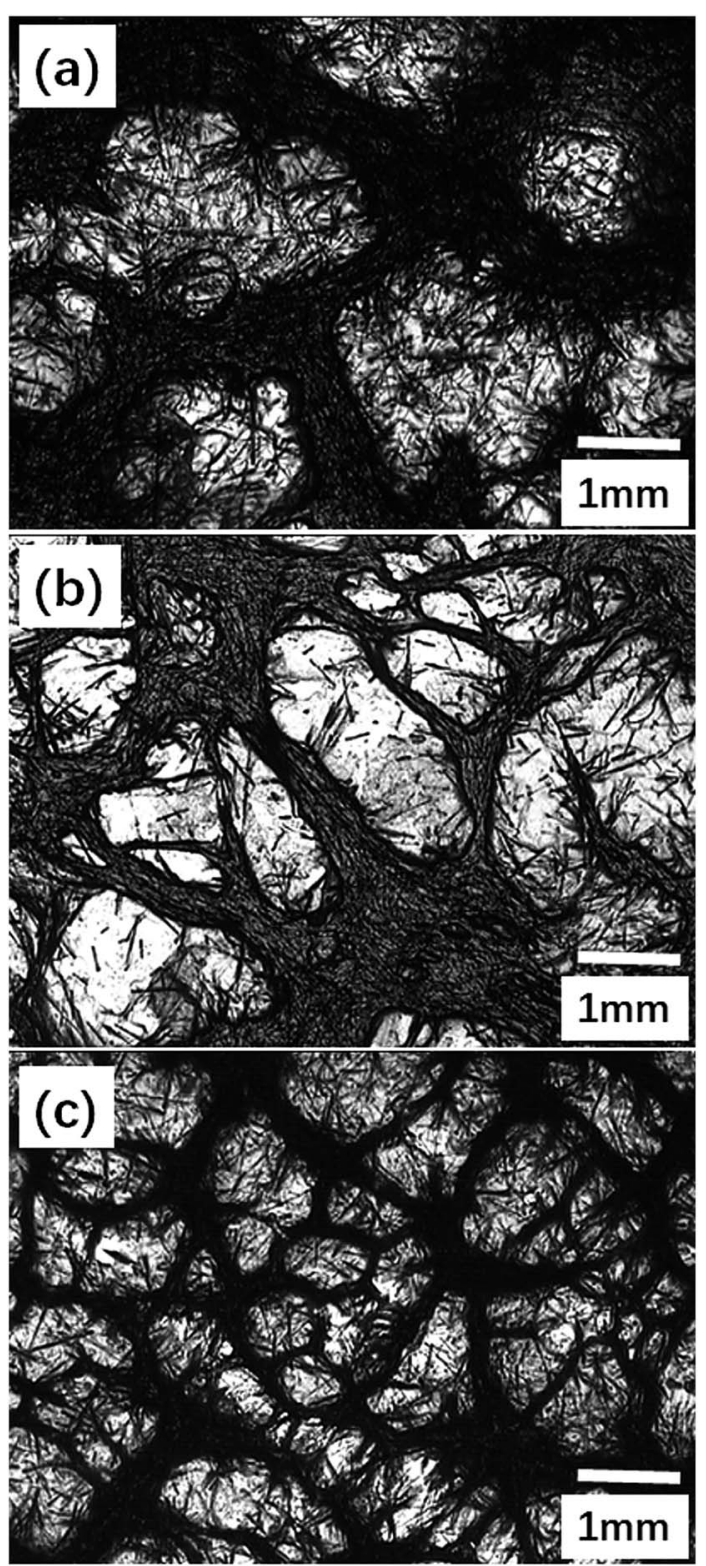

Fig. 6 (a-c) Micrographs of PDMS/4 wt\% SCF composite sheets surface by P3 of T4, T3 and T1, respectively. 
Fig. 5 shows the relationships between direct current (DC) electrical conductivity and SCF content for PDMS/SCF composite sheets of $\mathrm{T} 1, \mathrm{~T} 2, \mathrm{~T} 3$ and $\mathrm{T} 4$ by the SCFNA with bolting cloth process, which follow the same change rule of P3 in Fig. 3 under the condition of invariable in thickness. Table 1 makes a list of the conductivity values of that compared with the compounding method. Known from the curve in Fig. 5 and the values in Table 1, the conductivity increased with the decrease of thickness of the composite sheets under the condition of same filler concentration. In detail, when the thickness of samples is $350 \mu \mathrm{m}$ or $450 \mu \mathrm{m}$, the conductivities of the samples change little and for $250 \mu \mathrm{m}$ its conductivity double improves, continue to $150 \mu \mathrm{m}$ its conductivity increases several times. Fig. $6 \mathrm{a}-\mathrm{c}$ are the micrographs of PDMS/4 wt\% SCF composite sheets surface by $\mathrm{P} 3$ of T4, T3 and T1, respectively, which show the whole situation of SCF conductive network. The characteristic diameters of the network are about $580 \mu \mathrm{m}, 440 \mu \mathrm{m}$ and $156 \mu \mathrm{m}$ marked on the figures, implying the SCF conductive network in PDMS was getting more and more compact and finegrained as the samples were compressed to a thickness from $450 \mu \mathrm{m}$ to $150 \mu \mathrm{m}$.

The dispersion and location of the carbon fibers in PDMS and the average gap between adjacent carbon fibers in the network was used to explain this rule (Fig. 7a-d). In T3 and T4, the compression of the sample could only cause the selfassembly network wiggling in polymer matrix without estimable densification of the network threads as the thickness of the samples is much large than characteristic diameter. The carbon fibers are self-assembly in PDMS with mild reunion phenomenon in certain spacing and the average gap of adjacent carbon fibers in the network is about $5 \mu \mathrm{m}$ (T3) and $10 \mu \mathrm{m}$ (T4). In contrast, for $\mathrm{T} 1$ and $\mathrm{T} 2$, when the sample was compressed to a thickness less than characteristic diameter, a noteworthy densification of the network threads could be come into being by forced compression of the mold to the network. The average

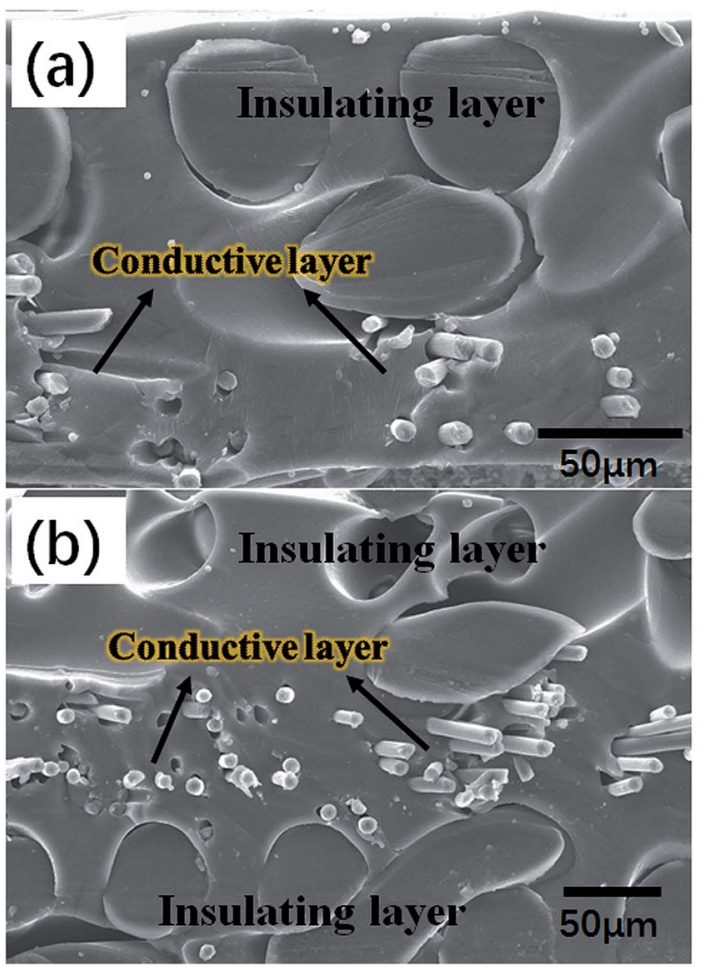

Fig. 8 (a and b) SEM micrographs of PDMS/4 wt\% SCF composites section of single insulating surface layer and double insulating surface layers by P3.

gap of adjacent carbon fibers in the network is less than $1 \mu \mathrm{m}$ (T2) and less than $100 \mathrm{~nm}$ (T1). In process of forced compression, the carbon fibers at the threads will tend to be more closely and exceeded polymer between the fillers at the threads will be squeezed out (Fig. 7a and b) because the wiggling freedom of the network has been restricted and the aggregate
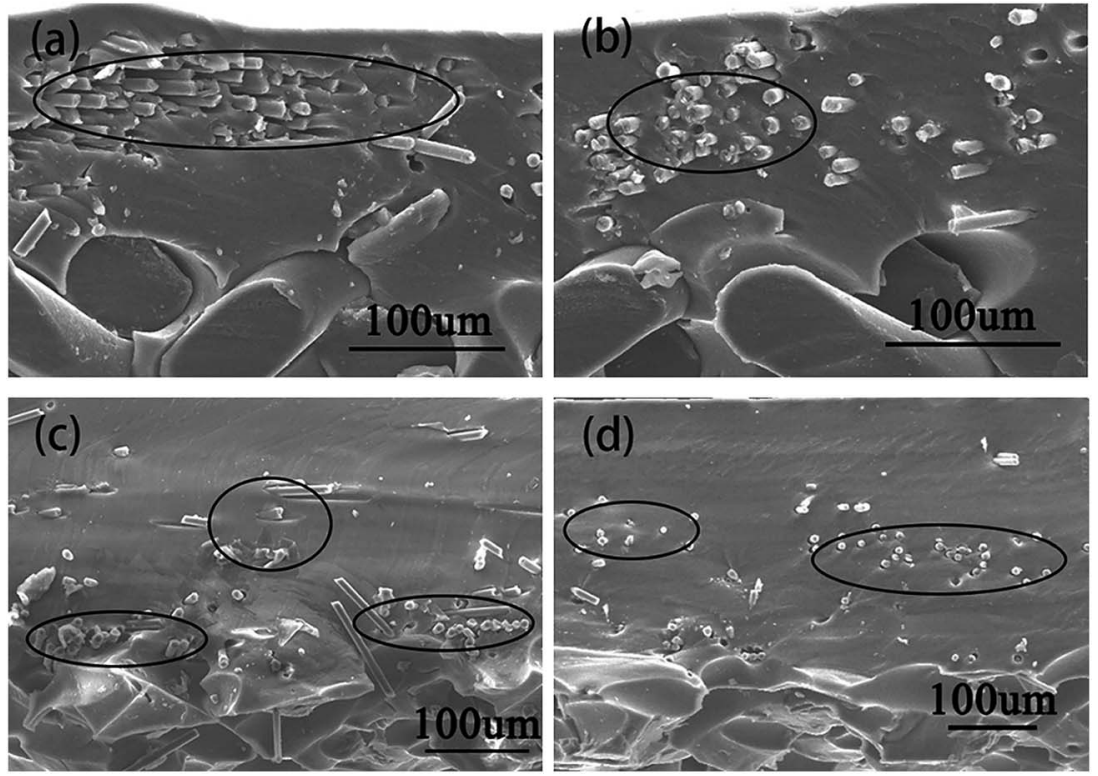

Fig. 7 (a-d) SEM micrographs of PDMS/4 wt\% SCF composites section of T1, T2, T3 and T4, respectively. 
Table 2 Surface resistivity of PDMS/4 wt\% SCF composite sheets with 0,1 and 2 layers of insulating surface by P3. BC is bolting cloth

\section{Surface resistivity $(\Omega)$}

\begin{tabular}{llll} 
Layers of BC & 0 & 1 & 2 \\
\hline Surface 1 & 45.0 & 21.1 & $8.59 \times 10^{6}$ \\
Surface 2 & 43.2 & $3.35 \times 10^{6}$ & $9.78 \times 10^{6}$
\end{tabular}

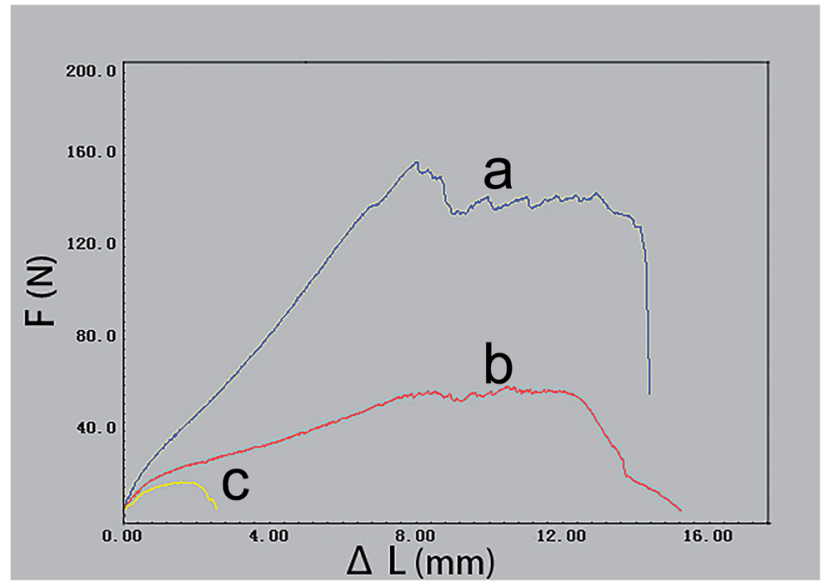

Fig. 9 The tensile curve of PDMS/4 wt\% SCF samples $(150 \mathrm{~mm} \times 20$ $\mathrm{mm} \times 0.3 \mathrm{~mm}$ ) with 0,1 and 2 layers of insulating surface by P3, marked with (c), (b), (a), respectively.

force between the fillers at the threads can prevent fillers from disaggregation.

In the practical engineering application, electro-conductive polymeric composites with surface insulation are usually needed. In this work, PDMS/SCF functional composite sheets with one insulating surface layer or double insulating surface layers were prepared by the SCFNA method with bolting cloth (Fig. $8 \mathrm{a}$ and b). And Table 2 shows the surface resistivity of PDMS $/ 4$ wt\% SCF composite sheets with 0,1 and 2 layers of insulating surface. In addition, different range of surface resistivity of composites could also be prepared by using different size of conductive fillers or different mesh number of bolting cloth.

The high electro-conductive PDMS/SCF composite sheets with bolting cloth prepared by the SCFNA method are not only high flexible because of high elastic PDMS, but also have excellent mechanical properties, as the addition of highstrength bolting cloth and carbon fibers. The tensile curve of samples $(150 \mathrm{~mm} \times 20 \mathrm{~mm} \times 0.3 \mathrm{~mm})$ reveal that the bolting cloth greatly improved the mechanical properties of materials (Fig. 9), especially for the PDMS/SCF composite sheets with 2 layers of bolting cloth, which tensile strength is several times higher than that of sheets without bolting cloth. The yield stress of samples with 0,1 and 2 layers of insulating surface are 2.82 MPa, 7.03 MPa, 23.06 MPa, respectively. As a result, both high electrical conductivity and mechanical properties were obtained by the SCFNA method with bolting cloth.

\section{Conclusions}

High electro-conductive polydimethylsiloxane(PDMS)/short carbon fiber (SCF) binary composites with a low percolation threshold of $0.15 \mathrm{wt} \%$ were prepared by a Spatial Confining Forced Network Assembly (SCFNA) method. The addition of bolting cloth further improved the electrical conductivity and the mechanical property of the composite sheets. A much lower percolation threshold of $0.06 \mathrm{wt} \%$ and a higher electrical conductivity of $3.22 \times 10^{2} \mathrm{~S} \mathrm{~m}^{-1}$ with $4 \mathrm{wt} \%$ of SCF were obtained due to the volume exclusion effect. The analysis of dispersion and location of the carbon fibers in PDMS, the average gap between adjacent carbon fibers in the network and the micrographs of the SCF conductive network on the composite sheets surface were used to verify the effectiveness of the forced assembly. Compared with conventional compounding method, the electro-conductive properties of the composites prepared by above mentioned method can be enhanced up to several times, or even orders of magnitudes as a result of the action of forced assembly. Moreover, if the mesh number of the bolting cloth is large enough, the carbon fibers will be impeded from penetrating the bolting cloth together with the polymer when they are co-compressed, thus an electrically conductive film with single or double insulating face can be prepared through this method.

\section{Acknowledgements}

This work was supported by the National Natural Science Foundation of China (Grant No. 51673020) and China Postdoctoral Science Foundation (Grant No. 2016M600032).

\section{References}

1 Y. Q. Sun and G. Q. Shi, J. Polym. Sci., Part B: Polym. Phys., 2012, 51, 231-253.

2 H. L. Wang, Q. L. Hao, X. J. Yang, L. D. Lu and X. Wang, Nanoscale, 2010, 2, 2164-2170.

3 S. Stankovich, D. A. Dikin, G. H. B. Dommett, K. M. Kohlhaas, E. J. Zimney, E. A. Stach, et al., Nature, 2006, 442, 282-286.

4 Z. Y. Cao and B. Q. Wei, ACS Nano, 2014, 8, 3049-3059.

5 A. E. Jakus, E. B. Secor, A. L. Rutz, S. W. Jordan, M. C. Hersam and R. N. Shah, ACS Nano, 2015, 9, 4636-4648.

6 J. J. Liang, Y. Wang, Y. Huang, Y. F. Ma, Z. F. Liu, J. M. Cai, et al., Carbon, 2009, 47, 922-925.

7 Y. F. Xu, Y. Wang, J. J. Liang, Y. Huang, Y. F. Ma, X. J. Wan and Y. S. Chen, Nano Res., 2009, 2, 343-348.

8 L. Lin, S. Y. Liu, Q. Zhang, X. Y. Li, M. Z. Ji, H. Deng and Q. Fu, ACS Appl. Mater. Interfaces, 2013, 5, 5815-5824.

9 K. Suzuki, K. Yataka, Y. Okumiya, S. Sakakibara, K. Sako, H. Mimura and Y. Inoue, ACS Sens., 2016, 1, 817-825.

10 E. Roh, B. U. Hwang, D. Kim, B. Y. Kim and N. E. Lee, ACS Nano, 2015, 9, 6252-6261.

11 F. B. Madsen, A. E. Daugaard, S. Hvilsted and A. L. Skov, Macromol. Rapid Commun., 2016, 37, 378-413. 
12 L. X. Wang, H. L. Peng, X. L. Wang, X. Chen, C. S. Yang, B. Yang and J. Q. Liu, Microsyst. Nanoeng., 2016, 2, 16065.

13 S. S. Hassouneh, L. Y. Yu, A. L. Skov and A. E. Daugaard, J. Appl. Polym. Sci., 2017, 134, 44767-44775.

14 Y. L. Ma, D. M. Wu, Y. Liu, X. F. Li, H. Qiao and Z. Z. Yu, Composites, Part B, 2014, 56, 384-391.

15 H. Deng, L. Lin, M. Z. Ji, S. M. Zhang, M. B. Yang and Q. Fu, Prog. Polym. Sci., 2014, 39, 627-655.

16 H. Pang, L. Xu, D. X. Yan and Z. M. Li, Prog. Polym. Sci., 2014, 39, 1908-1933.

17 R. Balint, N. J. Cassidy and S. H. Cartmell, Acta Biomater., 2014, 10, 2341-2353.

18 K. K. József, M. Haroon and P. Alessandro, Prog. Mater. Sci., 2015, 73, 1-43.

19 E. Bekyarova, E. T. Thostenson, A. Yu, H. Kim, J. Gao, J. Tang, H. T. Hahn, T. W. Chou, M. E. Itkis and R. C. Haddon, Langmuir, 2007, 23, 3970-3974.

20 H. Qian, A. R. Kucernak, E. S. Greenhalgh, A. Bismarck and M. S. P. Shaffer, ACS Appl. Mater. Interfaces, 2013, 5, 61136122.

21 M. Shtein, R. Nadiv, M. Buzaglo, K. Kahil and O. Regev, Chem. Mater., 2015, 27, 2100-2106.

22 E. Tkalya, M. Ghislandi, W. Thielemans, P. V. D. Schoot, G. D. With and C. Koning, ACS Macro Lett., 2013, 2, 157-163.

23 E. Tkalya, M. Ghislandi, R. Otten, M. Lotya, A. Alekseev, P. V. D. Schoot, et al., ACS Appl. Mater. Interfaces, 2014, 6, 15113-15121.

24 S. M. Zhang, H. Deng, Q. Zhang and Q. Fu, ACS Appl. Mater. Interfaces, 2014, 6, 6835-6844.

25 H. Simzar, M. R. Sayed, V. F. Ebrahim, M. Matin, Z. Soheila and S. Masoud, Polymer, 2016, 97, 205-216.

26 F. M. AL-Oqla, S. M. Sapuan, T. Anwer, M. Jawaid and M. E. Hoque, Synth. Met., 2015, 206, 42-54.

27 Z. L. Hou, W. L. Song, P. Wang, M. J. Meziani, C. Y. Kong, A. Anderson, et al., ACS Appl. Mater. Interfaces, 2014, 6, 15026-15032.
28 X. Q. Ji, Y. H. Xu, W. L. Zhang, L. Cui and J. Q. Liu, Composites, Part A, 2016, 87, 29-45.

29 V. C. Lokhande, A. C. Lokhande, C. D. Lokhande, J. H. Kim and T. Ji, J. Alloys Compd., 2016, 682, 381-403.

30 Z. Stary, J. Krückel, C. Weck and D. W. Schubert, Compos. Sci. Technol., 2013, 85, 58-64.

31 N. J. S. Sohi, S. Bhadra and D. Khastgir, Carbon, 2011, 49, 1349-1361.

32 K. Alper, D. Akın and D. Ali, Composites, Part B, 2014, 62, 113-120.

33 T. Wiriya, R. J. Spontak and C. M. Balik, Polymer, 2002, 43, 3717-3725.

34 X. Y. Qi, D. Yan, Z. G. Jiang, Y. K. Cao, Z. Z. Yu, F. Yavari and N. Koratkar, ACS Appl. Mater. Interfaces, 2011, 3, 3130-3133.

35 D. Yan, H. B. Zhang, Y. Jia, J. Hu, X. Y. Qi, Z. Zhang and Z. Z. Yu, ACS Appl. Mater. Interfaces, 2012, 4, 4740-4745.

36 C. Mao, Y. T. Zhu and W. Jiang, ACS Appl. Mater. Interfaces, 2012, 4, 5281-5286.

37 G. Q. Tang, Z. G. Jiang, X. F. Li and Z. Z. Yu, Carbon, 2014, 77, 592-599.

38 R. Haggenmueller, C. Guthy, J. R. Lukes, J. E. Fischer and K. I. Winey, Macromolecules, 2007, 40, 2417-2421.

39 E. Y. Li and N. Marzari, ACS Nano, 2011, 5, 9726-9736.

40 C. M. Chang and Y. L. Liu, ACS Appl. Mater. Interfaces, 2011, 3, 2204-2208.

41 Y. Kato, M. Horibe, S. Ata, T. Yamada and K. Hata, RSC Adv., 2017, 7, 10841-10847.

42 D. Han, Y. H. Zhao, S. L. Bai and W. C. Ping, RSC Adv., 2016, 6, 92168-92174.

43 C. H. Zhu, L. M. Li, J. H. Wang, Y. P. Wu and Y. Liu, RSC Adv., 2017, 7, 51-57.

44 R. Socher, B. Krause, S. Hermasch, R. Wursche and P. Pötschke, Compos. Sci. Technol., 2011, 71, 1053-1059.

45 S. Kirkpatrick, Rev. Mod. Phys., 1973, 45, 574-588.

46 I. Chakraborty, K. J. Bodurtha, N. J. Heeder, M. P. Godfrin, A. Tripathi, R. H. Hurt, A. Shukla and A. Bose, ACS Appl. Mater. Interfaces, 2014, 6, 16472-16475. 